\author{
RITA RAKOWSKA
}

Instytut Ochrony Przyrody PAN

Adama Mickiewicza 33, 31-120 Kraków

E-mail: rakowska@iop.krakow.pl

\title{
UDOSTEPNIANIE INFORMACJI O RÓŻNORODNOŚCI EUKARYOTA Z ZASOBÓW INSTYTUTU OCHRONY PRZYRODY POLSKIEJ AKADEMII NAUK W RAMACH PROJEKTU IMBIO I ICH ZNACZENIE W OCHRONIE PRZYRODY
}

Istniejący już przeszło 100 lat Instytut Ochrony Przyrody Polskiej Akademii Nauk (IOP PAN) przy Al. Adama Mickiewicza $33 \mathrm{w}$ Krakowie jest jednostka naukowa wchodzaca w skład II Wydziału Nauk Biologicznych i Rolniczych PAN. Jej celem jest działanie na rzecz ochrony przyrody, co realizuje poprzez badania terenowe i laboratoryjne, polegajace na dokumentowaniu stanu przyrody oraz ocenę zagrożeń dla różnorodności biotycznej. Uzyskane wyniki są wdrażane m.in. w postaci planów działań, strategii i aktów prawnych. Bardzo istotnym elementem działań jest także popularyzacja wiedzy dotyczacej zagrożeń i ochrony przyrody.

Instytut nie posiada $\mathrm{w}$ swoich zasobach dużych zbiorów okazów, gdyż ich gromadzenie nigdy nie było $w$ jego strategicznych planach. Niewielkie kolekcje tworzone przez pracowników, służące głównie do weryfikacji oznaczeń taksonomicznych, były przez nich zbierane niejako przy okazji prowadzenia badań dotyczacych rozmieszczenia gatunków. Zgromadzone $\mathrm{w}$ ten sposób dane nie były dotychczas udostępniane. $\mathrm{W}$ ramach realizacji projektu IMBIO (Integracja i mobilizacja danych o różnorodności biotycznej Eukaryota $\mathrm{w}$ zasobach polskich instytucji naukowych) zasoby te sa digitalizowane i udostępniane $\mathrm{w}$ postaci rekordów danych poprzez sieć GBIF (ang. Global Biodiversity Information Facility). Sa to głównie dane pochodzace $z$ notatek terenowych (łacznie ponad 26000 rekordów), w tym m.in. dotyczace rozmieszczeniu roślin na cmentarzach, pta- ków w krajobrazie rolniczym oraz płazów i gadów w Polsce południowej (Tabela 1).

Specyficznym zbiorem Instytutu jest „Kartoteka lęgów bociana białego”. Sa to ankiety danych zebranych $z$ obszaru całej Polski, które dotycza oceny populacji bociana białego, Ciconia ciconia (Linnaeus, 1758) w jego zasięgu geograficznym. Pierwsze liczenia gatunku rozpoczęto $\mathrm{w}$ Galicji w II połowie XIX w., ale wyłącznie cztery liczenia dały możliwość oszacowania liczebności jego polskiej populacji (WUCZYŃSKI i współaut. 2019). W ramach obecnej digitalizacji tej kartoteki zostana udostępnione dane ankietowe w liczbie 30000 rekordów, pochodzace $z$ ogólnokrajowych cenzusów tego ptaka $z$ lat 1958, 1974, 1994 i 2004, a także z Dolnego Śląska, z lat 1984 i 1989. Dotychczas informacje te nie były nigdy kompleksowo analizowane. Opracowano jedynie część tego zbioru, co pozwoliło m.in. na stwierdzenie, że po 1958 r. doszło do spadku liczebności bociana białego w Polsce. Późniejszy wzrost tej populacji do 47 400-52 700 osobników, szacowany w latach 2013-2018, nie był jednak równomierny $\mathrm{w}$ całym kraju, ponieważ w kilku regionach (np. na Ślasku i na Mazurach) doszło do znacznych spadków liczebności tego gatunku (WUCZYŃSKI i współaut. 2019). Digitalizacja i udostępnienie całości kartoteki szerszemu gronu odbiorców pozwoli na szczegółowe analizy trendów populacji bociana białego, zarówno w skali ogólnopolskiej, jak też lokalnej. Możliwe będa także analizy preferencji gniazdowych,

Słowa kluczowe: GBIF, Instytut Ochrony Przyrody Polskiej Akademii Nauk, łąki Karpat, różnorodność Eukaryota

*Artykuł powstał dzięki wsparciu finansowemu z projektu POPC.02.03.01-00-0081/19 „Integracja i mobilizacja danych o różnorodności biotycznej Eukaryota w zasobach polskich instytucji naukowych" (IMBIO). 


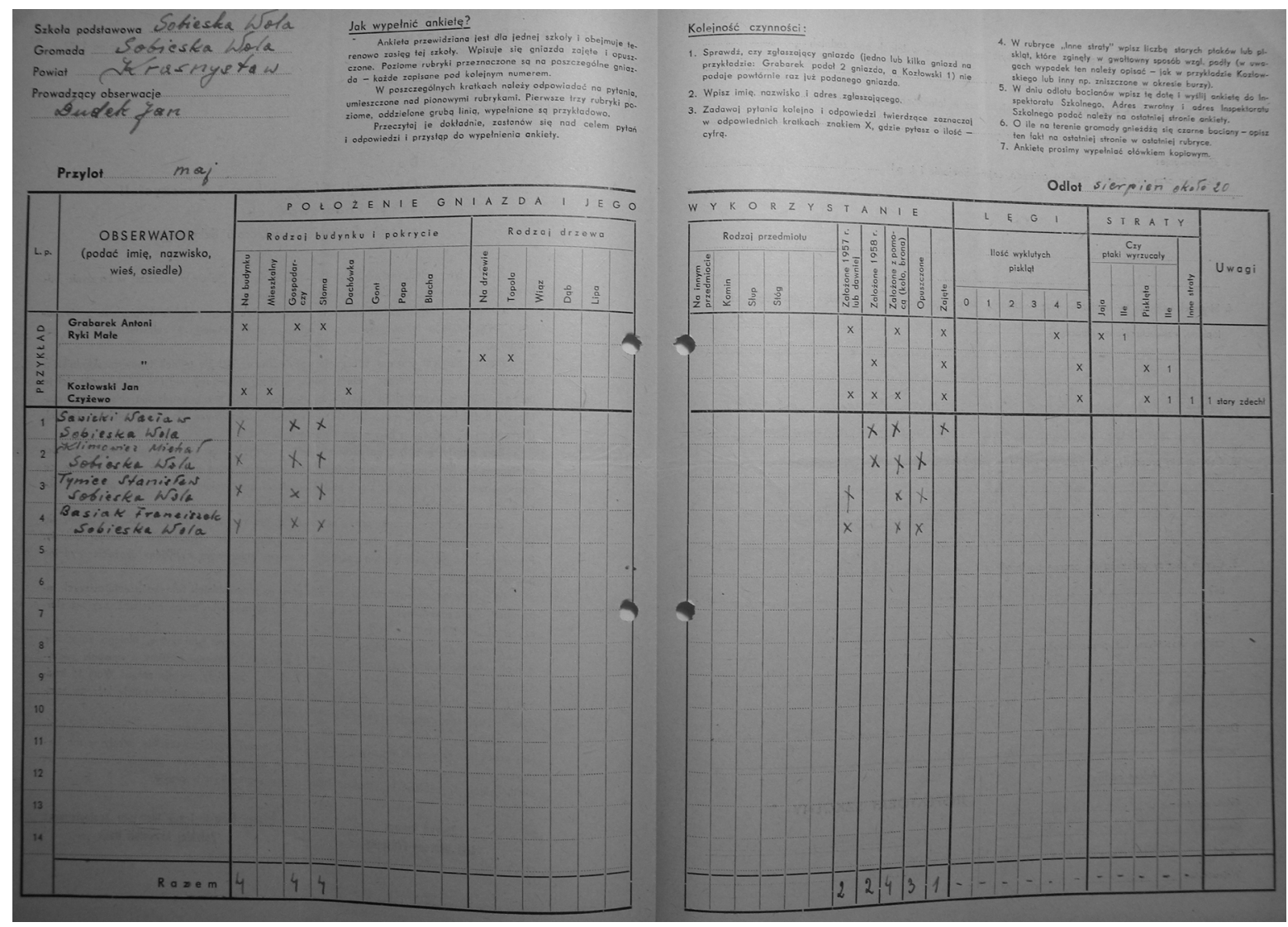

Ryc. 1. Formularz ankiety z ogólnopolskiego liczenia bociana białego z 1958 r. z powiatu Krasnystaw. Ankieta przedstawia czas przylotu i odlotu, położenie i wykorzystanie gniazda, lęgi oraz straty w osobnikach (fot. Wiesław Król).

sukcesu lęgowego, przyczyn śmiertelności, a także danych fenologicznych, np. terminy przylotu i odlotu tych ptaków. Informacje te przyczynia się do lepszego poznania biologii gatunku w kontekście czasoprzestrzennym. Dokumentacja fotograficzna ankiet (Ryc. 1, 2, 3) umożliwi ponadto zachowanie ich oryginalnej treści, w tym danych, które nie sa bezpośrednio zwiazane $z$ biologia bociana białego, np. informacje o stosunku lokalnej ludności do tego gatunku, a także o wierzeniach $\mathrm{i}$ przesadach $z$ nim zwiazanych (Ryc. 2, 3) (WUCZYŃSKI i współaut. 2019). W przyszłości dane te moga również posłużyć np. do badań socjologicznych dotyczacych zmian postaw społeczeństwa w stosunku do bociana białego na przestrzeni ponad 60 lat.

Trzecim rodzajem udostepnianych rekordów danych sa informacje $z$ czterech względnie obszernych baz danych będacych w obecnych zasobach IOP PAN. Część $z$ tych danych nie była dotychczas powszechnie dostępna. Dzięki projektowi IMBIO również te informacje zostana upublicznione poprzez GBIF szerokiemu gronu zainteresowanych odbiorców. W ten sposób zostana także włączone informacje dotychczas udostępniane jedynie przez serwery IOP PAN. Sumaryczna liczba wszystkich uporządkowanych i odpowiednio opisanych rekordow danych o bioróżnorodności wybranych grup systematycznych Eukaryota przekroczy 170000.

Najwięcej (98 000) rekordów danych zawiera baza danych „Łaki w Karpatach Polskich" (rośliny naczyniowe i mszaki), powstała w 2007 r. Baza ta obejmuje zdjęcia fitosocjologiczne $z$ półnaturalnych i antropogenicznych zbiorowisk łakkowych oraz psiar polskich Karpat. Dotychczas zgromadzono 5893 zdjęć fitosocjologicznych w oparciu o źródła publikowane i niepublikowane oraz dane uzyskane $z$ programu „Monitoring gatunków i siedlisk przyrodniczych ze szczególnym uwzględnieniem specjalnych obszarów ochrony siedlisk Natura 2000", który został Instytutowi zlecony przez Głównego Inspektorat Ochrony Środowiska. Założeniem tej bazy było prowadzenie okresowych obserwacji i analiz (monitoring) stanu zachowania łak w Karpatach, co umożliwi lepsza ich ochronę i zarządzanie zasobami przyrodniczymi (KORZENIAK 2013, https://www.iop. krakow.pl/LakiKarpat/). Udostępnienie tak obszernego spektrum danych dotyczacych rozmieszczeniu roślin na obszarach górskich może być szczególnie istotne do analiz i oce- 


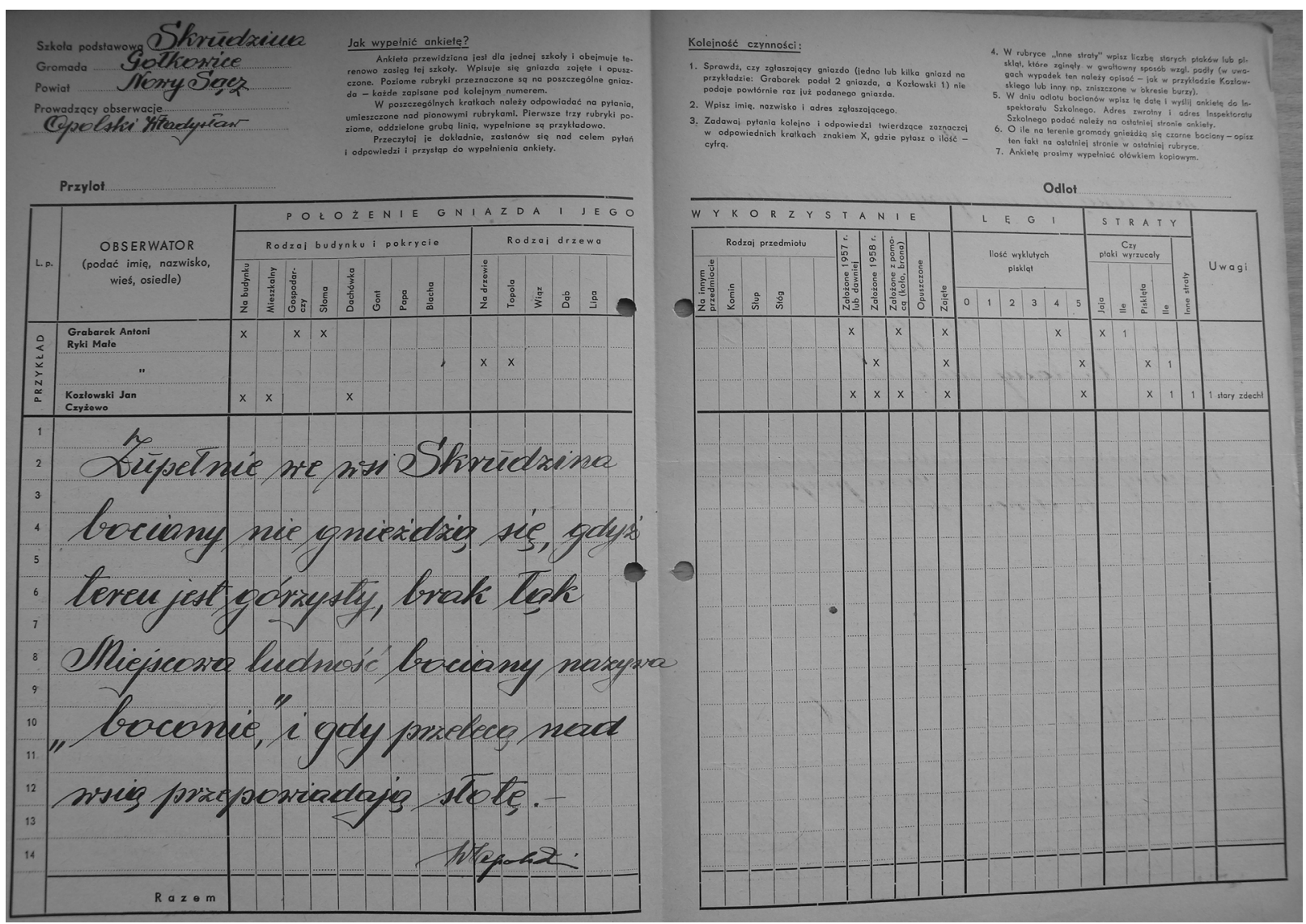

Ryc. 2. Ankieta z 1958 r. $z$ powiatu Nowy Sącz z wpisem „Zupełnie we wsi Skrudzina bociany nie gniazduja się, teren jest górzysty, brak łak. Miejscowa ludność bociany nazywa „boconie” i gdy przeleca nad wsią przepowiadaja słotę" (fot. Wiesław Król).

ny skutków antropopresji (np. rolnictwa) oraz zmian klimatycznych, na co obszary te są szczególnie narażone i uwrażliwione.

Znaczna liczbę (52 000) szeroko udostępnianych rekordów danych w ramach projektu IMBIO stanowi także baza danych pt. „Atlas Ssaków Polski”. Jej wersja internetowa (https://www.iop.krakow.pl/Ssaki/) powstała jako kontynuacja i aktualizacja wydanego wcześniej atlasu w formie książkowej (PUCEK i RACZYŃSKI 1983). Celem tej bazy jest przedstawienie rozmieszczenia wszystkich ssaków, zarówno pospolitych, jak i zagrożonych. Warto dodać, że dzięki dużej liczbie obserwacji zgłoszonych przez szerokie grono osób w trakcie realizacji tego projektu, atlas stanowi obecnie jedno $z$ najbardziej kompleksowych źródeł informacji dotyczacych rozmieszczenia ssaków w Polsce. Obecny atlas zawiera również mapy ukazujące rozmieszczenie wszystkich 114 gatunków ssaków, które zostały dotychczas wykazane na obszarze kraju w jego obecnych granicach. Jednak część $z$ tych danych ma obecnie jedynie znaczenie historyczne, gdyż wiele stanowisk zniknęło lub pewne gatunki od dawna się już nie pojawiły w Polsce (https://www.iop.krakow.pl/Ssaki/).
Również informacje $z$ bazy pt. „Atlas Płazów i Gadów Polski”, liczace 21000 rekordów danych, znajdą się światowej sieci GBIF, dzięki projektowi IMBIO. Ta względnie niedawno powstała baza cyfrowa, udostępniana przez Internet (https://www.iop. krakow.pl/plazygady) stanowi uzupełnienie wcześniej wydanych atlasów w formie książkowej (GŁOWACIŃSKI i RAFIŃSKI 2003, GŁOWACIŃSKI i SURA 2018). Znajdują się w niej również mapy rozmieszczenia 19 gatunków płazów i 12 gatunków gadów wykazanych obecnie na obszarze Polski. Podobnie jak w przypadku atlasu ssaków, najnowsze informacje o płazach i gadach pochodza zarówno od osób zwiazanych ze środowiskiem naukowym, jak również entuzjastów obserwujacych te kregowce.

Osobny zbiór udostępnianych rekordów danych obejmuje baza danych pt. "Gatunki Obce w Polsce". Problem gatunków obcych, w kontekście oddziaływania gatunków inwazyjnych na rodzima bioróżnorodność zyskał w ostatnich latach na znaczeniu (np. GŁOWACIŃSKI i współaut. 2012, TOKARSKA-GUZIK i współaut. 2012, NAJBEREK i SOLARZ 2016). Inwazje biologiczne stały się jednym 


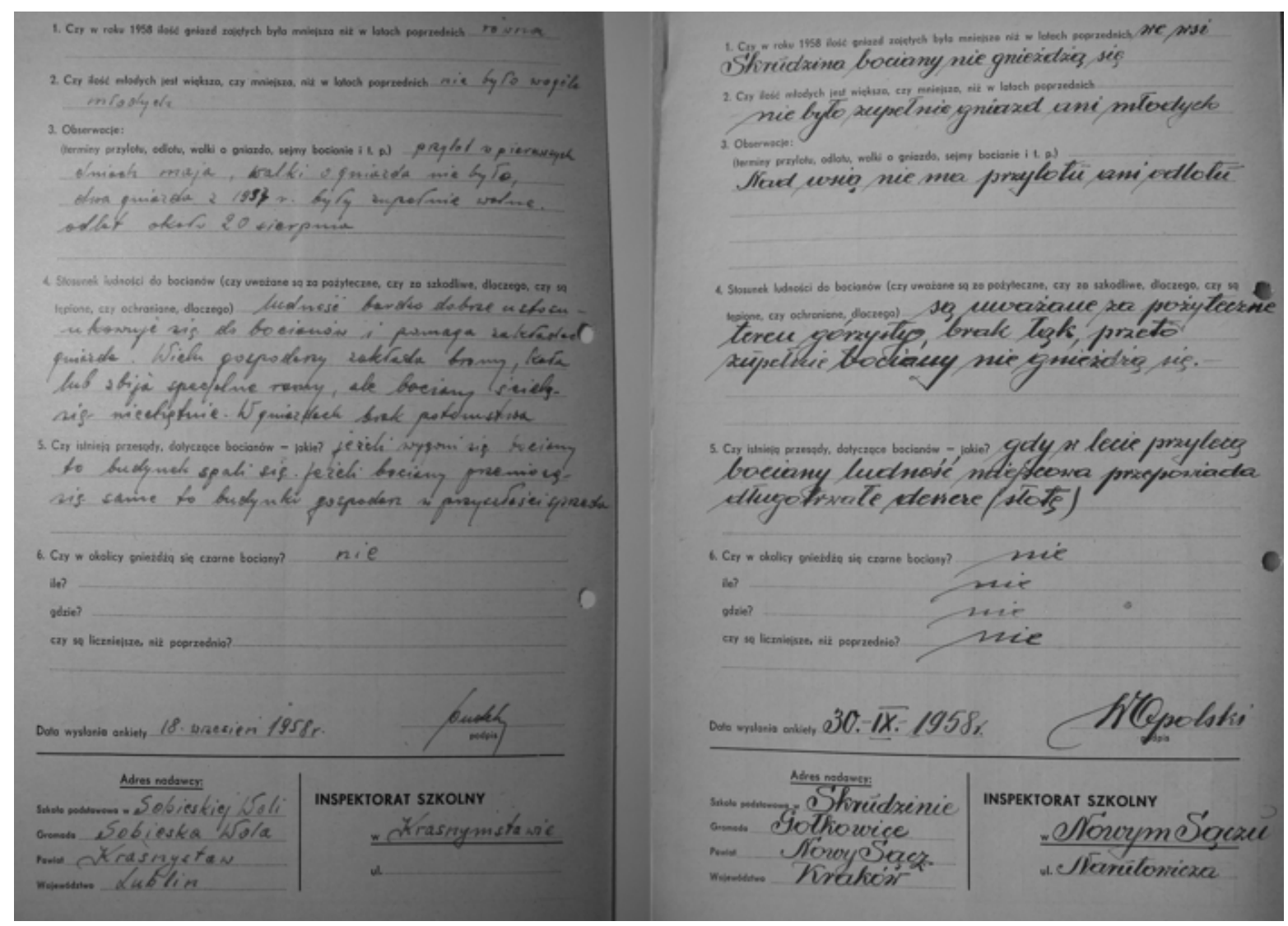

Ryc. 3. Druga strona ankiet z 1958 r. z powiatów Krasnystaw (po lewej) i Nowy Sacz (po prawej) zawierająca oprócz wpisów dotyczacych występowania bocianów (m.in. liczba osobników, przylot, walki o gniazdo) podejście i przesądy mieszkańców (fot. Wiesław Król).

z głównych tematów badawczych oraz działań wdrożeniowych i popularyzatorskich prowadzonych przez IOP PAN. Gromadzenie danych dotyczacych gatunków obcych rozpoczęto w IOP PAN już w 1999 r. Od 2003 r. dane te sa udostepniane poprzez Internet (https://www.iop.krakow.pl/ias). Baza danych „Gatunki Obce w Polsce” zawiera obecnie informacje o 1787 gatunkach reprezentujących różne taksony mikroorganizmów, grzybów, roślin i zwierząt. W ramach realizacji projektu IMBIO lista tych gatunków zostanie zaktualizowana i uzupełniona o dodatkowe informacje, np. stanowiska oraz dokładne lokalizacje stwierdzeń ich obecności. Ponadto, gatunki zostana sklasyfikowane w zależności od ich statusu oraz stopnia inwazyjności, w tym typu i stopnia negatywnego oddziaływania na rodzima przyrodę, gospodarkę, a także zdrowie i życie ludzi. Uzupełniony zostanie również wykaz źródeł informacji o występowaniu gatunków obcych w Polsce.

Tabela 1. Zbiory danych Instytutu Ochrony Przyrody PAN pochodzace $z$ terenowych notatek pracowników wraz $z$ liczbą rekordów digitalizowanych w ramach realizacji projektu IMBIO.

\begin{tabular}{ll}
\hline Nazwa zbioru & Liczba rekordów \\
\hline Rośliny cmentarzy południowej Polski & 6000 \\
Ptaki lęgowe i zimujące w urozmaiconym krajobrazie rolniczym Przedgórza Sudeckiego & 5000 \\
Płazy i gady południowej Polski & 5000 \\
Ważki Małopolski i Pojezierza Pomorskiego & 4000 \\
Wrotki zbiorników antropogenicznych w Polsce & 3500 \\
Okrzemki południowo-wschodniej Polski & 3000 \\
Krasnorosty południowej Polski & 150 \\
\hline
\end{tabular}


Upowszechnianie przez środowisko naukowe zrozumiałej i łatwej do przyswojenia dla szerszego grona odbiorców wiedzy (np. w formie wykładów czy artykułów popularnonaukowych), jest bardzo istotne dla zwiększenia społecznego poparcia badań i poprawy skuteczności działań ochronnych na rzecz rodzimej przyrody. Udostępnianie zasobów danych o różnorodności biotycznej organizmów jądrowych będących w zasobach IOP PAN w Krakowie w ramach projektu IMBIO, wpisuje się w pełni w strategię informowania i przybliżania efektów badań także osobom nie mającym na co dzień styczności $z$ nauka i ochrona przyrody. Ponadto, działanie to będzie komplementarne do projektu OZwRCIN (Otwarte Zasoby w Repozytorium Cyfrowym Instytutów Naukowych), w ramach którego IOP PAN bezpłatnie udostępnia część zdigitalizowanych prac naukowych i popularnonaukowych, opublikowanych w ramach swoich wydawnictw. Taka forma popularyzacji wiedzy jest szczególnie efektywna w obecnej dobie łatwego, powszechnego i bezpłatnego dosteppu do informacji za pomocą Internetu. Należy mieć nadzieję, że dzięki tym pracom, wysiłki środowiska naukowego i szeroko pojętego społeczeństwa, zostana jeszcze lepiej zintegrowane i przyczynią się do poprawy stanu rodzimej przyrody.

\section{PODZIEKOWANIA}

Serdecznie dziękuję mgr. Wiesławowi Królowi za udostępnienie zdjęć $z$ „Kartoteki lęgowej bociana białego" oraz dr. hab. Wojciechowi Solarzowi prof. IOP PAN za pomoc w przygotowaniu niniejszego tekstu.

$$
\text { Streszczenie }
$$

Instytut Ochrony Przyrody Polskiej Akademii Nauk (IOP PAN) digitalizuje i udostępnia część swoich zasobów informacji o różnorodności Eukaryota w ramach projek- tu IMBIO (Integracja i mobilizacja danych o różnorodności biotycznej Eukaryota w zasobach polskich instytucji naukowych). Udostępniane dane pochodzace $z$ notatek $z$ badań terenowych pracowników Instytutu, dotycza m.in. roślin cmentarzy Polski południowej, a także ważek Małopolski i Pojezierza Pomorskiego. Najwięcej rekordów danych (150 000) dostarczaja bazy danych „Laki w Karpatach Polskich” i „Atlas Ssaków Polski”. Mamy nadzieję, że udostępnienie zasobów danych o różnorodności krajowych Eukaryota w ramach projektu IMBIO przyczyni się nie tylko do szerszego zainteresowania społeczeństwa nauka, ale również do efektywniejszej ochrony polskiej przyrody.

\section{LITERATURA}

GŁOWACIŃSKI Z., RAFińsKi J., 2003. Atlas płazów $i$ gadów Polski. Status-Rozmieszczenie-Ochrona. Biblioteka Monitoringu Środowiska, Inspekcja Ochrony Srodowiska w Warszawie, Instytut Ochrony Przyrody PAN, Kraków.

GŁOWACIŃSKI Z., SURA P., 2018. Atlas płazów $i$ gadów Polski. Status-Rozmieszczenie-Ochrona, z kluczami do oznaczania. Wydawnictwo Naukowe PWN SA, Warszawa.

GŁOWACIŃSKI Z., OKARMA H., PAWŁOWSKI J., SOLARZ W., 2012. Gatunki obce $w$ faunie Polski. Wyd. internetowe. Instytut Ochrony Przyrody PAN, Kraków.

KORZENIAK J., 2013. Scope and data set of the phytosociological database 'Grasslands in the Polish Carpathians'. Acta Soc. Bot. Pol. 82, 237-242.

NAJBEREK K., SOLARZ W., 2016. Gatunki obce. Przyczyny inwazyjnych zachowañ $i$ sposoby zwalczania. Kosmos 65, 81-91.

PUCEK Z., RACZYŃSKI J., 1983. Atlas rozmieszczenia ssaków $w$ Polsce. PWN, Warszawa.

TOKARSKA-GUZIK B., DAJDOK Z., ZAJAC M., ZAJAC A., URBISZ A., DANIELEWICZ W., HoŁDYŃSKI C., 2012. Rośliny obcego pochodzenia $w$ Polsce. Generalna Dyrekcja Ochrony Środowiska, Warszawa.

WuczyŃSki A., Krogulec G., Neubauer G., ProFUS P., 2019. Pierwsza ocena liczebności bociana białego Ciconia ciconia $w$ Polsce $w$ 1958 roku - streszczenie prezentacji. Chrońmy Przyr. Ojcz. 75, 336-344. 
KOSMOS Vol. 70, 2, 197-202, 2021

\author{
RITA RAKOWSKA
}

Institute of Nature Conservation PAS, 33 Adama Mickiewicza Av., 31-120 Kraków, E-mail: rakowska@iop.krakow.pl

PROVIDING INFORMATION ON EUKARYOTA'S DIVERSITY FROM THE RESOURCES OF THE INSTITUTE OF NATURE CONSERVATION OF THE POLISH ACADEMY OF SCIENCES AS PART OF THE IMBIO PROJECT AND THEIR IMPORTANCE IN NATURE CONSERVATION

\title{
Summary
}

The Institute of Nature Conservation of the Polish Academy of Sciences (IOP PAN) digitizes and provides access to some of own information resources on Eukaryota's diversity as part of the IMBIO project (Integration and mobilization of data on Eukaryota's biotic diversity in the resources of Polish scientific institutions). Shared data from field research notes of the Institute's researchers, concerning incl. the plants of the cemeteries of southern Poland, as well as dragonflies of Małopolska region and the Pomeranian Lake District. Most of the data records $(150,000)$ are provided by the databases "Meadows in the Polish Carpathians” and „Atlas of Mammals of Poland”. We hope that making the data resources on the Eukaryota diversity in Poland available under the IMBIO project will contribute not only to wider public interest in science, but also to more efficiency of nature conservation in the country.

Key words: Carpathian meadows, Eukaryota biodiversity, GBIF, Institute of Nature Conservation of the Polish Academy of Sciences 